\title{
Response related factors in recombinant interferon alfa-2b treatment of chronic hepatitis $\mathrm{C}$
}

\author{
R Pérez, R Pravia, A Linares, M Rodríguez, J L S Lombraña, A Suárez, S Riestra, \\ C A Navascués, L Rodrigo
}

\begin{abstract}
In an analysis of the clinical and laboratory variables that can influence the response to interferon alfa-2b treatment, 48 patients with chronic hepatitis $C$ virus infection received interferon 5 million units (MU) subcutaneously three times weekly for eight weeks followed by 3 MU three times weekly for seven months. Response related factors on univariate analysis were found to be age $>\mathbf{4 0}$ years, non-parenteral source of infection, pretreatment positive antinuclear antibodies (ANA), cirrhosis, and high serum iron, ferritin, gamma glutamyl transferase, and IgM. An independent predictive value (multivariate analysis) was also found for cirrhosis, ANA, serum iron, and ferritin. A baseline aspartate aminotransferase/ alanine aminoransferase ratio of 0.5 and a striking increase during interferon treatment were associated with a complete response.
\end{abstract}

(Gut 1993; supplement: S139-S140)

The influence of clinical and laboratory variables on the response to interferon was analysed in patients with chronic hepatitis C who were positive for antibodies to hepatitis C virus (anti-HCV) on both ELISA-2 and RIBA-2.

\section{Patients and methods}

Forty eight patients (33 men and 15 women) aged 18-65 years (mean (SD): $41.5(13.8)$ ) were included in the study. Thirty one $(64 \cdot 6 \%)$ had chronic active hepatitis and $17(35 \cdot 4 \%)$ had cirrhosis. The presumed source of $\mathrm{HCV}$ infection was blood transfusion in 19 patients $(39.6 \%)$, intravenous drug abuse in seven $(14.6 \%)$, professional exposure in five $(10.4 \%)$, tattoos in one $(2.1 \%)$, major surgery in 10 $(20 \cdot 8 \%)$ and unknown (sporadic) in six $(12 \cdot 5 \%)$.

Interferon alfa-2b (INTRON A) was given subcutaneously at a dose of 5 million units (MU) three times a week for eight weeks, followed by $3 \mathrm{MU}$ three times a week for seven months. The data were analysed statistically using Student's $t$ test, the $\chi^{2}$ test, and Cox's stepwise logistic regression.

\section{Results}

Twenty one $(43.7 \%)$ of the 48 patients achieved a complete response to therapy (that is, a return to normal serum alanine aminotransferase (ALT) activities at month nine). Twelve $(25 \cdot 0 \%)$ had a partial response (a decrease in ALT to less than $50 \%$ of baseline values), and $15(31 \cdot 2 \%)$ had no response (no change in ALT or a decrease to greater than $50 \%$ of baseline values)

Response related factors (univariate and multivariate analyses) are shown in Tables I and II. Baseline serum iron and ferritin concentrations were significantly lower in complete response patients compared with both partial and no response patients (iron: complete $v$ partial response, $\mathrm{p}=0.0012$, complete $v$ no response, $\mathrm{p}=0.0058$; and ferritin: complete $v$ partial response, $\mathrm{p}=0.00001$, complete $v$ no response, $\mathrm{p}=0.004$.) Normal baseline serum iron and ferritin concentrations were found to be more frequent in patients with chronic active hepatitis than in those with cirrhosis $(p=0.005$ and $\mathrm{p}=0 \cdot 028$, respectively).

The baseline aspartate aminotransferase (AST)/ALT ratio was significantly lower in complete $(p=0.0005)$ and partial response patients $(p=0.001)$ than in no response patients. A striking increase in the AST/ALT ratio during IFN treatment was seen in complete, but not in partial and no response patients (Figure).

TABLE I Response related factors (univariate analysis)

\begin{tabular}{|c|c|c|c|c|}
\hline & $C R$ & $P R$ & $N R$ & p value * \\
\hline Age $>40$ years & 9 & 3 & 11 & 0.036 \\
\hline $\begin{array}{l}\text { Presumed non-parenteral infection } \\
\text { (surgery and sporadic) }\end{array}$ & 6 & 1 & 9 & 0.015 \\
\hline Pretreatment positive ANA $\nmid$ & 3 & 3 & 9 & 0.012 \\
\hline Active cirrhosis & 4 & 3 & 10 & 0.008 \\
\hline $\begin{array}{l}\text { Serum iron values high } \\
(>140 \mu \mathrm{g} / \mathrm{dl})\end{array}$ & 6 & 9 & 11 & 0.007 \\
\hline $\begin{array}{l}\text { Serum ferritin values high } \\
\quad(>300 \mu \mathrm{g} / \mathrm{l} \text { men }) \\
(>130 \mu \mathrm{g} / \mathrm{l} \text { women })\end{array}$ & 1 & 8 & 8 & 0.0003 \\
\hline $\begin{array}{l}\text { Serum gamma glutamyl transferase } \\
\text { high }(>50 \text { IU } / 1)\end{array}$ & 7 & 8 & 12 & 0.014 \\
\hline Serum IgM high (>250 mg/dl) & 2 & 0 & 5 & 0.034 \\
\hline
\end{tabular}

${ }^{\star} \chi^{2}$ test (Yates's correction where necessary).

tANA: antinuclear antibodies, titre $=1: 80$.

$\mathrm{CR}=$ complete; $\mathrm{PR}=$ partial; $\mathrm{NR}=$ no response.

TABLE II Response related factors (multivariate analysis ${ }^{*}$ )

Independent predictive value for response versus non-response $\begin{array}{ll}\text { Chronic active hepatitis versus cirrhosis } & \mathrm{p}=0.002 \\ \text { Negative versus positive antinuclear antibodies } & \mathrm{p}=0.003\end{array}$ Independent predictive value for a non-complete response

Independent predictive value for a non-complete response
High serum iron values

High serum iron values

High serum ferritin values
Positive antinuclear antibodies

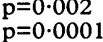

*Stepwise logistic regression according to the Cox model. 


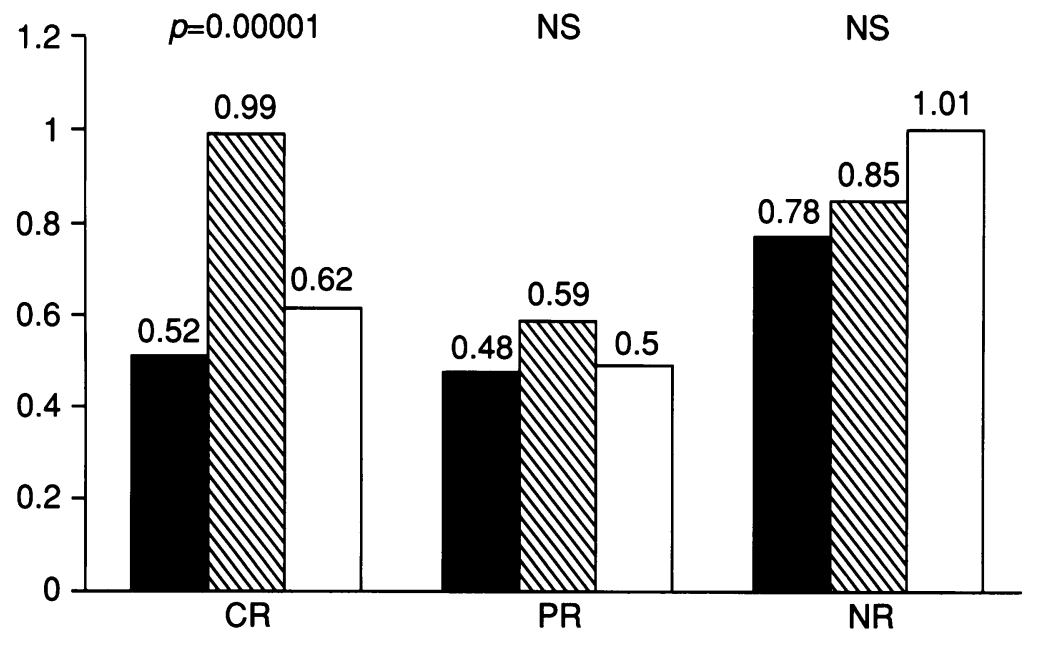

Baseline
MW Interferon

Post interferon

\section{Conclusions}

From these results, it can be concluded that the 'typical' patient with no or a partial response to interferon treatment is more than 40 years old with presumed non-parenteral infection, pretreatment positivity for antinuclear antibodies (ANA), cirrhosis, and high serum iron, ferritin, gamma glutamyl transferase, and IgM values. An independent predictive value was found for cirrhosis, ANA, and serum iron and ferritin values. Patients with chronic active hepatitis usually have normal baseline serum and ferritin values.

Finally, a baseline AST/ALT ratio of about 0.5 and a striking increase in this ratio during interferon treatment are associated with a complete response.

Figure Aspartate aminotransferase/alanine aminotransferase ratio according to response to interferon treatment. $C R=$ complete, $P R=$ partial, and $N R=$ no response. 